\title{
Papers
}

Explorations into Children's Literature

\section{'try-error-try-it': Love, Loss, and the Subversion(?) of the Heteronormative Romance Story in Will Grayson, Will Grayson}

\author{
Dr. Dion McLeod - The University of Wollongong
}

\begin{abstract}
"and that's how you find it ... you know, it" (268). Romances stories are often about finding happiness and true love, about finding it. In these novels happiness is both privileged and equated with love, and more often than not these love stories are about heterosexual happiness. Sara Ahmed, in The Promise of Happiness, describes the necessity of queer love stories when she explains "there are of course good reasons for telling stories about queer happiness, in response to and as a response to the very presumption that a queer life is necessarily and inevitably an unhappy life" (p. 94). My article explores this presumption by examining John Green and David Levithan's Will Grayson, Will Grayson (2010), specifically the way the novel encourages empathy for the queer characters by playing with the readers' generic and social expectations of the romance story.

Will Grayson, Will Grayson follows two teenage boys named Will Grayson, whose paths cross serendipitously. The chapters of this novel present simultaneous love stories by alternating between straight Will (who ends up in stable monogamous heterosexual relationship, and therefore has a normatively happy ending) and gay Will (whose future is not so certain). This paper contrasts the hetero- and homosexual love stories and analyses how the interplay of these stories engenders empathy in the reader. I argue that in this way, Will Grayson, Will Grayson challenges heteronormative expectations of the romance story.
\end{abstract}

Keywords: Queer, Will Grayson, John Green, David Levithan, Romance, Young Adult

'that's our curse and our blessing. that's our trial and our error and our it'

(Green and Levithan 2010, p. 310, italics original)

Romance novels tell stories about finding true love, about finding it. These romance stories often follow a woman as she searches for Mr. Right (in other, fewer cases, a man searching 
for Mrs. Right). Romance stories usually focus on the trials and tribulations of a heterosexual couple, and the young adult romance novel 'typically characterises romantic relationships in almost exclusively heterosexual terms and underscores the "compulsory heterosexuality" present in both the genre and the larger world outside the text' (Pattee 2008, p. 159). One of a growing number of young adult novels to explore a same-sex romance is John Green and David Levithan's Will Grayson, Will Grayson', which includes a simultaneous narration of a hetero- and homosexual love story.

Throughout this article I refer to "queer" (un)happiness. The term "queer" has a multitude of meanings and is used variously by different scholars. When using the term "queer," I am talking about an identity more complex than simply "lesbian," "gay," or "bisexual"; "queer" refers to someone who deviates from expected norms of gender and sexuality. I do not, however, want to fall in to the trap of conflating numerous identities, named or unnamed, under the category of "queer." Exploring this precarious positioning in Making Things Perfectly Queer: Interpreting Mass Culture, Alexander Doty notes:

I find myself working with sexual identity terms in the service of not-quitecompatible goals. I want to construct 'queer' as something other than 'lesbian,' 'gay,' or 'bisexual'; but I can't say that 'lesbian,' 'gay,' or 'bisexual' aren't also 'queer.' I would like to maintain the integrity of 'lesbian,' 'gay,' and 'bisexual' as concepts that have specific historical, cultural, and personal meanings; but I would also like 'lesbian,' 'gay,' and 'bisexual' culture, history, theory, and politics to have some bearing on the articulation of queerness. (1993, p. xvii)

"Queer" is a loaded term with a long history of pathologisation and reclamation. Throughout this paper when I deploy the term "queer" I do so with recognition of this history and ambiguity surrounding it. I refer to "gay Will" when discussing the character and "queer" when talking about the wider queer community to which Will and queer readers exist. 
In Will Grayson, narrative and sexuality are not only intertwined, but vital to an understanding of happiness and closure. Judith Roof and Sara Ahmed have explored the connection between narrative structure and (hetero)sexuality. In The Promise of Happiness, Ahmed moves beyond heterosexual narratives and describes the necessity of queer love stories when she explains 'there are of course good reasons for telling stories about queer happiness, in response to and as a response to the very presumption that a queer life is necessarily and inevitably an unhappy life' (2010, p. 94). I extend this general presumption about queer (un)happiness to the way(s) it influences or informs closure in Green and Levithan's romance novel, contrasting the hetero- and homosexual love stories and analysing how the interplay of these stories create empathy for the queer characters. In the novel, gay relationships are entertained, but narrative closure only becomes actualised for the straight relationship. Despite its lack of definitive narrative closure for the gay character, Will Grayson creates empathy for gay Will through straight Will. When I refer to (un)happiness in this article, I refer to the way certain characters are narratively afforded an opportunity for closure; happiness (joy) is often associated with the path towards a monogamous relationship, while unhappiness (misery) is associated with a disruption to that path. Though the novel in some ways upholds this 'unhappy life' trope - as will be shown in this paper - it nevertheless engenders empathy in the reader. It is as a result of this engendering, I argue, that the novel challenges heteronormative expectations of the romance story.

Will Grayson contains two love stories told simultaneously in alternating chapters. The oddnumbered chapters, written by John Green, follow the story of Will Grayson, a straight boy who struggles to abide by his 'two very simple rules [to remain happy]: 1. Don't care too much. [and] 2. Shut up' (p. 5). The even-numbered chapters, written by David Levithan, follow the story of Will Grayson, a gay boy who struggles with both his sexuality and navigating the queer dating world. The individual stories of these two boys intersect when they wind up in a Chicago porn store in which neither had planned to be. For both Wills, the story that unfolds is their search for happiness. 
Will Grayson encourages the reader to feel stronger empathy for one Will through the happiness, pain, and heartache of the other. As Clare Hemmings notes in 'Invoking Affect,' affect 'is transferred to others and doubles back, increasing its original intensity. Affect can . .. place the individual in a circuit of feeling and response, rather than [in] opposition to others' (2005, p. 552, italics original). The novel itself creates a circuit in which the happiness or sadness of one Will passes through the reader and is projected onto the other Will. It is this circuit that forms the foundation of narrative closure throughout the novel.

In Come as You Are: Sexuality and Narrative, Judith Roof explores the relationship between narrative closure and reader satisfaction:

Without the expectation of an ending, we have difficulty discerning a story, its pleasures, terrors, lessons ... If there is no end we normally identify as an endorgasm, death, marriage . . .-we ask, "Is that all there is?" and regard the apparently truncated story as ironic, as an unsatisfying failure. $(1996$, p.6)

While the heterosexual narrative in Will Grayson is not an 'unsatisfying failure' because of the ending afforded to straight Will, the queer narrative is more ambiguous. By the end of the novel, a (queer) reader may indeed ask, 'was that all?' Will Grayson demonstrates the continued difficulty of representing a happy gay romance in a YA contemporary realist setting. As Amy Pattee notes in relation to another gay YA novel, Levithan's Boy Meets Boy, '[i]n young adult literature, perhaps more so than in adult literature, homosexual romance requires a utopian setting for the romance's conclusion to be considered genuinely blissful' (p. 159). Unlike Boy Meets Boy, Will Grayson is not a utopian novel. Throughout this article I explore the satisfaction (or bliss) that arises from the glimmer of queer happiness at the conclusion of the novel and how the text invites a reader to see this happiness as comparable to the satisfaction stemming from the unquestionable closure of the heterosexual narrative. 
Straight Will has a relatively 'straight' path to happiness. He experiences the conventional narrative arc of the heteronormative love story: 'boy meets girl, boy loses girl, boy gets girl' (Juhasz, p. 65). In contrast, gay Will has extreme highs and lows, therefore, when his story ends on a positive note (albeit not an explicit guarantee of happiness), it makes the journey appear all the more satisfying. Roberta Seelinger Trites explains how texts about gay teenagers 'promise the reader freedom from past constraints, freedom from continued repression, freedom from narrow-minded discourse' (1998, p. 143). She does note, however, that 'such books often undermine that alleged liberation, as if the very existence of the genre gay YA literature depended on repression' (p. 143). Because Will Grayson both undermines and supports the notion that a queer life is 'inevitably an unhappy life' (Ahmed 2010, p.94), the story of gay Will, and Will Grayson as a text is what Eve Sedgwick would call 'kinda subversive, kinda hegemonic' (1993b, p. 15). Through the interrelation of the two love stories, the text appears to subvert the 'unhappy queer' trope - though when one looks just beyond the happy heterosexual ending, this trope still clearly exists within the narrative.

The intersecting love stories of Will Grayson draw in six main characters: Will Grayson, Jane, Tiny, Will Grayson, Maura, and Isaac. The first three are introduced in straight Will's story. Straight Will a wealthy 17-year-old straight boy, is also an outcast, due in part to his abrupt manner and emotionally vacant personality. Straight Will meets his soon-to-be-girlfriend Jane after being dragged to a meeting of the school's Gay-Straight Alliance by Tiny. At this meeting, straight Will asks Tiny '...is Jane the gay part of the Gay-Straight Alliance or the straight part?' (p. 11). Within the first chapter of the novel the love interest for straight Will is introduced and his story is able to proceed. The third character in the story of straight Will is his best friend, Tiny - a theatrical, often dramatic, gay boy described as having a new boyfriend every hour. Because of his relationship with/to both Wills throughout the story, Tiny acts as a bridge between the two separate narratives. While one reading of the novel could suggest that the primary narrative is about Tiny's relationship with each Will, I suggest that, as would seem evident from the title, its primary concern is actually the romantic relationships of the Wills. Tiny's role as a mediating figure is important to the narrative, but does not overshadow the romance narratives. 
Gay Will Grayson is a 17-year-old who struggles with both his mental health and sexuality. For gay Will, even the simple act of going to school daily becomes a struggle. Gay Will's closest friend is a girl named Maura, who he does not particularly like. Maura, while at times wanting a romantic relationship with gay Will, also openly questions his sexuality, a factor that only further pushes her away from him. The only positive aspect of gay Will's life is his online relationship with Isaac, which he keeps hidden from everyone, 'because it's none of their business. $i$ [sic] love that he knows who everyone is but nobody knows who he is' ( $p$. 32). Each Will has one friendship as a matter of convenience and one romantic interest that he pursues.

Pamela Demory and Christopher Pullen explore representations of generic expectations of romance, noting;

Romance is central not only to the conventional romance genre-in which a heterosexual couple navigates various barriers to love and eventually reaches a happy, monogamous union - but also to less generic explorations of love, within couples, marriages, and families, in which closure restores the couple or family unit (in the "happy ending") or fails to restore "normal" order (in the unhappy or open ending). ... . But this is a story from which . . . gays and lesbians have historically been excluded.' (2013, pp. 1-2).

Within the novel, the narrative closure that arises from 'it' (described below) is represented as the ideal, and this closure is afforded only to straight Will and Jane. Only two conversations occur between both Wills in the text, both at the end of the novel.

In an online discussion that exemplifies how happiness is represented for both Wills, gay Will (willupleasebequiet), who has already experienced two breakups in the course of the novel talks to straight Will (WGrayson7) about the difficulties of relationships: 
willupleasebequiet: i just wish it wasn't all trial and error.

willupleasebequiet: because that's what it is, isn't it?

willupleasebequiet: trial and error.

willupleasebequiet: i guess there's a reason they don't call it "trial and success"

WGrayson7: if you'd caught me two weeks ago, i would have had to agree with you fullheartedly.

WGrayson7: now i'm not so sure.

willupleasebequiet: why?

WGrayson7: well, i agree that "trial and error" is a pretty pessimistic name for it. and maybe that's what it is most of the time.

WGrayson7: but $\mathrm{i}$ think the point is that it's not just try-error.

WGrayson7: most of the time it's try-error-try

WGrayson7: try-error-try

WGrayson7: try-error-try

WGrayson7: and that's how you find it.

willupleasebequiet: it?

WGrayson7: you know. it.

willupleasebequiet: yeah, it.

willupleasebequiet: try-error-try-it

WGrayson7: well ... i haven't become that optimistic.

WGrayson7: it's more like try-error-try-error-try-error-try-error-tryerror- try . . . at least fifteen more rounds . . . then try-error-try-it. (pp. 268-69, italics original)

This conversation raises the question of what exactly it is. Within Will Grayson I suggest that it is narrative closure associated with long-term heterosexual monogamy. Ahmed references the desire to find it when she explains that 'heterosexual love becomes about the possibility of a happy ending; about what life is aimed toward, as being what gives life direction or 
purpose, or as what drives a story' (2010, p. 90). By the time the above conversation occurs, the reader knows that straight Will's path to happiness, the end of his story (it), and the direction of his life is relatively smooth. His path is not so much try-error (x21)-it, but ironically - as he says he is not 'that optimistic' - his path is try-error-try-it. But for the queer character, gay Will, this path is try-error-try-error-try with only a possibility of it on the final page of the novel.

As the novel progresses and the stories continue to intersect, the text produces a feeling of ambivalence in regards to the (un)happiness of both Wills. I analyse this ambivalence by exploring how Will Grayson defines and locates happiness, both for the heterosexual and the queer. ' $I$ ' becomes allied to discussions of sexuality, closure, and happiness. As noted above, throughout the course of the novel straight Will becomes romantically involved with Jane and his story follows the classic 'boy-meets-girl' story line: try-error-try-it. But for gay Will and his relationships, there are two extreme highs representing his two relationships, two extreme lows representing the dissolution of those relationships, and finally a neutral conclusion, one that ends with the promise of happiness: try-error-try-error-try-it?

In the novel both Wills do follow a similar story arc: they both have moments of happiness and unhappiness. But the important thing to recognise is the fact that gay Will is not afforded the same chance of happiness at the novel's conclusion as straight Will receives. At the novel's conclusion straight Will has an explicit, unambiguous romantic relationship whereas gay Will has an ambiguous, non-explicit romantic relationship.

But, because their stories are so similar, and because empathy is created for one character through the other (c.f. Hemmings), the text encourages a reading that sees the endings as comparable in terms of happiness.

It is this disjunction - a disjunction that exists in the fact that the notion of 'happiness' in the novel seems to have a different baseline stands, depending on whether the underlying relationship is queer or straight - that begins to challenge heteronormative expectations of the romance story. This seeming contradiction between the comparable endings and the 
disjuncture exists because of a paradox within the novel itself caused by the differing baseline standards of 'happiness' and the blending of the two Will Graysons into a unified Will. Ultimately, however, the novel addresses this contradiction by attempting to map gay Will's narrative arc onto straight Will's.

Julie Abraham further explores the mapping of queer stories onto heterosexual stories through lesbian romances:

There could be no "lesbian plot" equivalent to the heterosexual plot, because the construction of heterosexuality is in modern culture the construction of heterosexuality as the norm, and because the function of literary conventions, like all conventions, is to normalize.... [I]f lesbianism is to be represented in the way that heterosexuality is represented within the novel . . . it has to be represented through the heterosexual plot. $(2008$, p. 3)

\begin{abstract}
Abraham's observation that lesbian stories can only be represented through the heterosexual plot is problematised further in the depiction of the gay romance in Will Grayson. Despite the contemporary cultural climate in which queer acceptance is gaining momentum, the queer love story is unable to be mapped onto the traditional heterosexual love story.
\end{abstract}

Within the romance novel 'happiness' is both privileged and equated with love. This 'happiness' is the both the fulfillment of the characters within the text, but also the happiness of the reader as they identify and build empathy with the characters and obtain narrative closure and emotional release at the end of the novel. For straight Will, 'happiness' is located in and with Jane, the first character towards whom he feels any desire. Of the two Wills, his story is the more straightforward, or typical, love story, but it is also complex. This complexity arises through Will's negotiation of normative expectations as to how a straight boy should behave and act. 
Although he feels a connection with Jane, straight Will spends many weeks trying to navigate his feelings for her. When thinking about why he is hesitant to approach Jane, Will explains:

I realize this is not, like, boyish. I realize that properly speaking guys should only think about sex and the acquisition of it, and that they should run crotch-first toward every girl who likes them and etc. But: The part I enjoy most is not the doing, but the noticing. . . I l just want the pleasure of noticing these things at a safe distance-I don't want to have to acknowledge that I am noticing. I don't want to talk about it or do stuff about it. (p. 47, italics original)

Straight Will's emphasis on not wanting to 'talk' or 'do stuff about it,' but rather watch Jane 'from a safe distance,' shows his hesitation and anxiety about dating. Because he is male, Will believes that he is expected not to care or show feelings, but rather simply meant to desire sex. Will does not necessarily know why he feels the way he does, but his identification of stereotypical teenage boy behaviours as being the expected norm in his situation, and his inability to respond to his relationship results in a feeling of ambivalence for him. Here, happiness for straight Will does not come initially from a relationship with Jane, nor from 'the acquisition of sex,' but rather from the voyeuristic pleasure of noticing Jane's small quirks. Although straight Will enjoys watching Jane, he does not want to act upon his desires. Happiness is within reach, but by taking what he perceives is a nonnormative approach to relationships, this happiness, and the closure of his story, cannot yet come to fruition.

When examining how both boys interact with their preferred partner from a safe distance, we can once more see the interplay of both love stories. While straight Will prefers to watch Jane from afar, gay Will has been dating Isaac, a boy he meets and only communicates with online, for about a year. Shortly before the two boys plan to meet in person for the first time, Isaac sends an email to Will encapsulating the feelings of chaos and disjointedness that the boys feel in their non-virtual life. In the email, Isaac says, 
i feel like my life is so scattered right now. like it's all these small pieces of paper and someone's turned on the fan. but talking to you makes me feel like the fan's been turned off for a little bit. like things could actually make sense. you completely unscatter me, and i appreciate that so much. (p. 37 , italics original)

For gay Will, Isaac is the one person who knows his sexuality and with whom he can be completely truthful. Upon receiving this email Will declares 'GOD I AM SO IN LOVE' (p. 37).

The respective relationships (Will and Jane/Will and Isaac) continue to flourish until the fateful night when both Wills meet each other for the first time. Straight Will's relationship with Jane blossoms as the pair begins to spend more time together. One winter's day, straight Will lends Jane his coat and later finds it inside his school locker. Inside his pocket is a note from Jane telling him to be careful because 'You never know (18) when someone (26) will memorize (4) your [locker] combination' (p. 84). This is the first occasion when Jane reciprocates the voyeuristic attitude of straight Will $\neg-$ a narrative device that connects the two of them more deeply.

Following the validation of his voyeurism, straight Will obtains Jane's locker number that leads to an error, the error, which stalls their relationship and leaves him alone in Chicago. Jane, Tiny, and straight Will plan a trip to Chicago to see their favourite band, the Maybe Dead Cats. Will finally understands his feelings for Jane, so on the afternoon of the performance he sends an email to the band asking them to dedicate a song to her locker number. Will's plan backfires at the last minute when the bouncer points out that his ID (a fake ID acquired earlier in the day) shows his age as 20. Being underage, Will is refused entry and tells his friends to go in without him. Little does Will know that this separation marks the occasion when his story enters the 'boy loses girl' phase.

Around the time that straight Will is abandoned, gay Will arrives in Chicago to meet Isaac for the first time. After a long train ride, he finds the meeting place only to discover that it is a 
porn store. On the off-chance Isaac is waiting inside Will enters the store, but sees only one other person, a boy his age-Will Grayson. The boys head outside and gay Will becomes deflated that he has been stood up by Isaac. The boys discover they share a name and begin to talk - the first conversation between them in the novel and the first time the two plots come together-and at that moment they receive simultaneous phone calls.

While straight Will talks to Tiny, gay Will answers a call from Maura. Maura tells him that Isaac will not be coming. Confused and angry, gay Will asks her what she means:

maura: i am isaac, will.

me: don't be stupid. he's a guy.

maura: no he's not. he's a profile. i made him up.

me: yeah, right.

maura: i did.

no. no no no no no no no no no no no no no

$\cdots$

newsflash: isaac never existed. it was only your friend posing. it was a lie. all a lie. (pp. 120-21)

At this moment gay Will's life is turned upside down. His anger, fear, anxiety, and desperation are initially seen through his denial ('don't be stupid') before being echoed, literally and typographically, by the repetition of the word 'no.'

This moment not only signals the end of gay Will's relationship with Isaac, but also the end his friendship with Maura. In a rage, he tells Maura;

you. despicable. cunt. . . it is only my respect for your parents that will prevent me from murdering you outright. but please understand this: i am never, ever speaking to you or passing notes to you or texting you or doing fucking sign 
language with you ever again. i would rather eat dog shit full of razor blades than have anything to do with you. (p. 122)

This conversation marks the destruction of gay Will's happiness and the possibility for his story's closure. As gay Will loses Isaac, straight Will is in the process of losing Jane-though it occurs a little later in the narrative sequence, this night is the night that Jane reunites with her ex-boyfriend. After straight Will has time for reflection on the events that unfolded, the experience of losing Jane becomes a moment of aperture, rather than a moment of rupture, and it facilitates the progression towards the closure of his love story. Conversely, loss for gay Will signals the cutting off of communication; the possibility for a happy ending ceases before it can fully develop. This rupturing of potential happiness (therefore an ending) is seen in the above dialogue both through gay Will's emphasis on the many ways he will not communicate with Maura-speaking (verbally), texting (electronically), and sign language (visually)-but also through his extreme language.

Gay Will's strong reaction to loss mirrors and emphasises the extreme lows in his story. This reaction is in contrast to straight Will, who appears to be less dramatic in his expression when he loses Jane. Alexander Doty, in Making Things Perfectly Queer, explains queerness as being related to anything 'contra-, non-, or anti-straight' (1993, p. xv). Using this definition, straight Will has a straight or 'appropriate' reaction to losing Jane. Gay Will, conversely, has a queer or 'inappropriate' reaction. But despite gay Will's reaction to his relationship break-up being much more severe than straight Will's, the text still encourages empathy towards him. The novel uses these reactions to once more conflate the stories of the two Wills to cause an affective circuit within the reader.

The above conversation between gay Will and Maura, and the one below between Jane and straight Will are a central moment in the novel that places the reader in a 'circuit of feeling' (Hemmings, p. 552). As the Wills talk about relationships, gay Will tells straight Will;

me: you know what sucks about love? 
o.w.g.: what?

me: that it's so tied to truth. (p. 125)

Gay Will recognises that his path to love, and therefore happiness, will not be simple. His love has been taken away from him by the realisation that it was based on a lie. This realisation is another connection between both Wills. In the novel, truth facilitates closure. Straight Will sees that gay Will's opportunity for closure has been ruptured by the lie from his perceived romantic partner, yet he still makes the decision to withhold his own truthhis true romantic feelings-from Jane.

After the Wills share their feelings on romance, their (future) romantic partners, Jane and Tiny, leave the club and join the two Wills. As Tiny consoles gay Will, straight Will approaches Jane. As he does so, he once more struggles internally with how he should act: 'I'm still thinking about the tying of love and truth-and it makes me want to tell her the truth-the whole, contradictory truth-because otherwise, on some level, am I not that girl? Am I not that girl pretending to be Isaac?' (p. 129). At this moment, straight Will realises his love for Jane (and therefore narrative closure) cannot come to fruition as long as there is an untruthful element to their relationship. When straight Will empathetically places himself into gay Will's position as a catalyst to further his own relationship with Jane, the reader, too, is empathetically aligned with the Wills. On one hand we lament the loss of gay Will and Isaac, but on the other we are optimistic for straight Will and Jane.

Straight Will goes for a walk with Jane, and after learning her ex-boyfriend was at the same club, suggests they spend 10 minutes talking openly and truthfully. Jane, however, reflects on her ex-boyfriend's presence and his attempt to win her back: 'turns out he had MDC dedicate a song to me... he's the only person who knows my locker combination, and he just had them dedicate it to my locker combination' (pp. 132-33). This moment is the error that acts as the obstacle to straight Will's happiness. Jane explains that this act by her exboyfriend is enough for her to resume their relationship. Will reflects once more on the events and notes, 'Even though these are the minutes of truth, I don't tell her about the 
song. I can't' (p. 133). Straight Will understands that love is connected with truth, yet he makes the decision to withhold the truth and to suffer the loss.

This connection of love and truth foreshadows the events that follow. Happiness for both boys becomes closely associated with truthfulness. For straight Will this truth is first revealed when, following the conversation with Jane, he realises he likes her more than he thought. Straight Will's truth is that he feels deeply for Jane and refuses to give up hope that the two will (re)unite romantically: 'I've never known before what it feels like to want someone-not to want to hook up with them or whatever, but to want them, to want them. And now I do' (p. 135, italics original). Because of his heterosexual attraction, straight Will is narratively provided the opportunity to follow the romance conventions - he found Jane, he lost Jane, and he will (re)gain Jane.

It does not take long before Jane ends up on the front porch of straight Will's house after realising her ex-boyfriend did not give the band her locker combination:

\footnotetext{
"What's my locker combination?"

"Twenty-five-two-eleven," I say.

She hits me playfully on the chest. "I knew it! Why didn't you tell me?"

"I couldn't figure out which of several things was the most true." (p. 223, italics original)
}

Straight Will accepts and admits the truth to both himself and Jane, and the novel narratively corrects the error on his path to happiness. Immediately following this revelation, Jane and Will cement their newfound relationship with a kiss, and Jane joins Will and his parents for dinner. This dinner shifts Will and Jane from the final 'try' into heterosexual happiness, confirmed climactically at the end of the novel where, when helping at a musical production at school, the two share a kiss on stage. Will meets Jane, Will loses Jane, and Will regains Jane. Try-error-try-lt. After following the traditional romance story (c.f. Juhasz), straight Will finds his partner. His story is able to close because he finds it after 
a literal error (of misinterpretation) made earlier by Jane. Will successfully navigates the error and, because his love story is heterosexual he is provided with the opportunity for closure: boy meets girl, boy loses girl, boy gets girl.

Romance novels are conventionally about the search for a heterosexual monogamous relationship, and as Abraham notes, 'heterosexual plots produce heterosexual endings' ( $p$. 6). Straight Will's relationship satisfies this search-the heterosexual plot he follows results in a heterosexual union with Jane. Because the novel tells two simultaneous stories, what remains is for gay Will to attempt to follow a parallel path in an effort to imitate this 'true' relationship. Immediately following the phone call with Maura, Tiny appears and comforts gay Will. The pair takes a walk through Chicago and before long they begin dating.

This new relationship lasts for a couple of months, during which time both gay Will and Tiny express more happiness than either have felt before. The love story of gay Will reaches another climax when Tiny meets and has dinner with Will's mother, and the two wind up in his bedroom - though nothing sexual happens. This meeting occurs only pages before Jane meets straight Will's parents and this parallel invites the reader to believe that a queer life is not necessarily an unhappy life. By interweaving the two stories and showing complementary events, the novel blurs the lines between both Wills. As a result of this blurring, the novel shifts the Wills from their position as independent characters towards one in which they become unified as a singular Will Grayson. With this transition, the focus of the readers' happiness also shifts towards the unified Will Grayson.

While both Wills are happy in their own relationships, the interplay of the stories becomes vital at this stage in the novel. Straight Will is dating Jane while gay Will is dating Tiny, but Tiny and straight Will have fallen out. Tiny only has room for one Will Grayson in his life. It is almost as though it is not possible for both Wills to exist in a happy state without disorder shortly following. The reader becomes invested in the happiness of both Wills in their respective relationships, even if it means this happiness results in an unhappiness caused by 
the deterioration of straight Will and Tiny's friendship. It does not take long following the climatic buildup of gay Will's moment of 'happiness' with Tiny before the pair breaks up.

Throughout the novel, happiness and happy endings become conditional on one another, and it becomes more apparent that although closure for the heterosexual is likely, closure for the queer is indeterminate. Marianna Torgovnick, in Closure in the Novel, explores the final moments of texts. She says, 'It is difficult to recall all of a work after a completed reading, but climactic moments, dramatic scenes, and beginnings and endings remain in the memory and decisively shape our sense of a novel as a whole' (1981, pp. 3-4, italics original). In Will Grayson, the most prominent moments that shape an understanding of the novel are gay Will's relationship breakdowns and straight Will and Jane's union. As a result, these two moments significantly shape a reading of the novel.

The novel suggests narrative closure for the traditional (straight) relationship is achievable (and imminent), but it does not offer similar hope for the queer relationship. As a result, it does not take long following the climatic buildup of gay Will's happiness with Tiny for the pair to break up. Here the novel once more backflips and appears to suggest that a queer life is necessarily an unhappy life-a happy ending exists only for straight Will.

By this stage in the novel gay Will has three failed relationships: Isaac, Maura, and Tiny. Will, along with the reader, begins to feel disheartened. Ahmed explains, '[q]ueer feelings are "affected" by the repetition of the scripts they fail to reproduce' (2014, p. 155). Will has been following the heteronormative 'try-error-try' storyline, though he is unable to narratively make the final leap to 'it.' He is, in essence, failing to reproduce the script that leads straight Will to closure.

The final relationship gay Will has that does not disintegrate is with a friend from schoolGideon. Will and Gideon meet shortly after Will is outed in front of the school. Gideon, no longer the only openly gay student, befriends Will. Gideon is present in Will's life from the emergence of Will's relationship with Tiny to his heartbreak following the breakup. 
The suggestion of hope for gay Will's future happiness, and the potential for narrative closure, comes when Will attempts to find someone for support following his breakup:

i figure i can go online and see if gideon's there. then i realize i can text him instead. then i realize i can call him. finally, i realize i can actually call him and see if he wants to do something because he's my friend, and that's what friends do. i call, he answers. i need him, he answers. i go over to his house and tell him what's happened, and he answers. it's not like it was with maura, who always wanted to take the dark road. it's not like it was with tiny, because with him i was feeling all these expectations to be a good boyfriend, whatever that is. no, gideon's ready to believe both the best and the worst in me. in other words: the truth. (p. 249)

Gay Will becomes aligned once more with straight Will through a realisation of those who surround him-Will realises that Gideon is there for support. Just as straight Will finds his truth in Jane, Gideon as a constant becomes gay Will's truth. Because of the novel's use of the term 'truth' and its variants, a potential romantic relationship between Gideon and Will is connoted in this scene.

The final scene in the novel takes place during a school musical directed by Tiny ii where straight Will and Jane kiss on stage-itself a public and acceptable declaration of their lovecementing their presumed long-term, heterosexual, monogamous relationship. Selinger and Gleason explain that while the romance genre was once predicated on 'happily ever after' 'a literal betrothal or marriage' - we now have 'a more casual understanding that the romantic partners [may] stay together and give the relationship a try . . the Happy For Now' (2016, pp. 6-7). While straight Will and Jane follow the conventions of the heterosexual romance, so their happy ending-Happy For Now-reifies the successful management of their relationship. 
Meanwhile, gay Will attends the same event with Gideon. As Gideon drives him to the play, Will thanks him for being a support throughout his relationship breakdowns and Gideon tells him that he would have done the same things, before saying 'pinkie swear, no lie' (p. 296). This one sentence is easy enough to overlook, but becomes significant in a search for queer happiness in the novel. On the final page, after heterosexual happiness is fulfilled, gay Will says the five words 'I link our pinkies again' (p. 310). This sentence itself is a small glimmer of hope that queer happiness will triumph, and when connected to 'pinkie swear, no lie' (p. 296) and the previous 'you know what sucks about love ... that it's so connected to truth' (p. 125), the novel presents a subtle indication that this is the beginning of their love story.

Thus, love (therefore a happy ending), for gay Will can only be connoted. Because of the interweaving of both Will's love stories and the happy ending for straight Will, a reader could assume gay Will will find love with Gideon. This assumption, however, leads to the question of how we define love. Ahmed also explores this notion:

I do wonder whether a queer definition of love might want to separate love from happiness, given how happiness tends to come with rather straight conditions. I thus offer Simone Weil's definition of love as a queer definition: "Love on the part of someone who is happy is the wish to share the suffering of the beloved who is unhappy. Love on the part of someone who is unhappy is to be filled with joy by the mere knowledge that his beloved is happy without sharing in this happiness or even wishing to do so." (2010, p. 100)

This alternate definition of love and happiness can be seen in gay Will and Gideon's relationship. Gideon shows love towards Will by sharing in his unhappiness (suffering), and Will reciprocates by knowing Gideon's happiness is enough for his own happiness. This would suggest that queer happiness (and love) could exist when two individuals are emotionally polar, so long as they are empathetic towards one another. 
The ultimate question then becomes where does the conclusion of Will Grayson situate queer happiness? As Eve Sedgwick explains;

I think many adults (and I am among them) are trying, in our work, to keep faith with vividly remembered promises made to ourselves in childhood: promises to make invisible possibilities and desires visible; to make the tacit things explicit; to smuggle queer representation in where it must be smuggled and, with the relative freedom of adulthood, to challenge queer-eradicating impulses frontally where they are to be so challenged. (1993a, p. 3)

And perhaps these childhood promises are the very reason(s) for determining whether a glimmer of queer happiness can be equated to full-fledged heterosexual happiness. The conventional romance novel concludes with a heterosexual monogamous relationship, and that is the end. That is the it that we are told we should aspire towards. But is that really enough for queer happiness?

Despite the fact that in today's cultural and social climate 'there is clearly more visible support for GLBTQ teens' (Cart and Jenkins 2006, p. 134), there is still stigma attached to those who date someone of the same gender. By their very nature, queer love stories cannot be mapped onto heterosexual love stories. But as Abraham notes, the 'heterosexual plot and its ideological effects could be challenged from within the formula of the lesbian novel. The protagonist does not have to be the one who comes to a heterosexual end' ( $p$. 13). The fact that the queer relationship in Will Grayson does not end in it is a positive sign after all, because this novel suggests that it is an ending; heterosexual love stories end, but queer love stories, because they are cumulative, can continue to flourish.

\section{Notes}

\footnotetext{
'Abbreviated to 'Will Grayson' throughout the remainder of this article

ii In March 2015, Levithan released Hold Me Closer: The Tiny Cooper Story, a novel that recounts Tiny's autobiographical musical. The release of this novel supports my suggestion that Tiny only plays a mediating role, and that Will Grayson is about more than his relationships with each of the Wills.
} 


\section{References}

Abraham, Julie (2008) Are Girls Necessary? Lesbian Writing and Modern Histories.

Minneapolis: University of Minnesota Press.

Ahmed, Sarah (2014) 'Queer Feelings.' In The Cultural Politics of Emotion. Edinburgh:

Edinburgh University Press, pp. 144-67.

- (2010) The Promise of Happiness. Durham: Duke University Press.

Cart, Michael and Jenkins, Christine A. (2006) The Heart Has Its Reasons: Young Adult Literature with Gay/Lesbian/Queer Content, 1969-2004.Lanham, MD: Scarecrow Press. Demory, Pamela and Pullen, Christopher (2013) 'Introduction.' In P. Demory and C. Pullen (eds) Queer Love in Film and Television: Critical Essays. New York: Palgrave Macmillan, pp. 19.

Doty, Alexander (1993) Making Things Perfectly Queer: Interpreting Mass Culture.

Minneapolis: University of Minnesota Press.

Green, John and Levithan, David (2010) Will Grayson, Will Grayson. New York: Dutton. Hemmings, Clare (2005) 'Invoking Affect: Cultural Theory and the Ontological Turn.' Cultural Studies 19 (5): 548-67.

Juhasz, Suzanne (1998) 'Lesbian Romance Fiction and the Plotting of Desire: Narrative Theory, Lesbian Identity, and Reading Practice.' in Tulsa Studies in Women's Literature 17 (1): 65-82.

Levithan, David (2015) Hold Me Closer: The Tiny Cooper Story. New York: Penguin Group. Pattee, Amy (2008) 'Sexual Fantasy: The Queer Utopia of David Levithan's Boy Meets Boy.' in Children's Literature Association 33 (2): 156-171.

Roof, Judith (1996) Come As You Are: Sexuality and Narrative. New York: Columbia University Press.

Sedgwick, Eve Kosofsky (1993) 'Queer and Now.' In Tendencies. Durham: Duke University Press, pp. 1-22.

- (1993) 'Queer Performativity: Henry James's The Art of the Novel.' GLQ: A Journal of Lesbian and Gay Studies 1 (1): 1-16. 
Selinger, Eric Murphy and Gleason, William A. (2016) 'Introduction: Love as Practice of Freedom?' In W. Gleaon and E. Selinger (eds) Romance Fiction and American Culture: Love as the Practice of Freedom? New York: Routledge, pp. 1-22.

Torgovnick, Marianna (1981) Closure in the Novel. Princeton: Princeton University Press. Tries, Roberta Seelinger (1998) 'Queer Discourse and the Young Adult Novel: Repression and Power in Gay Male Adolescent Literature,' Children's Literature Association Quarterly 22 (3): $143-51$.

\footnotetext{
Biographical Note

Dr. Dion McLeod completed a PhD in the School of the Arts, English and Media at the University of Wollongong, Australia in 2016. His PhD dissertation examined the representation of villains as queer in animated Disney films. He is currently working on expanding his dissertation into a monograph and is working on a co-edited book exploring politics, fandom, and social media. He recently published a co-authored paper, 'The Ghost of J.K. Rowling: Harry Potter and the Ur-Fan,' in Working Paper Series.
} 